\title{
Impact of Different CAM Strategies and Cutting Parameters on Machining Free-Form Surfaces with Ball-End Milling Tools in Terms of Micro and Macro Accuracy
}

\author{
Bálint Varga, Balázs Mikó \\ Institute of Material and Manufacturing Science, Óbuda University \\ Népszínház u. 8, H-1081 Budapest, Hungary \\ e-mail: varga.balint@bgk.uni-obuda.hu,miko.balazs@bgk.uni-obuda.hu
}

\begin{abstract}
The use of free-form surfaces is becoming more common in everyday life. Ergonomic, aesthetic, aerodynamic and fluid dynamics aspects also help their spread. The paper examines the CAM aspects of machining the free-form surfaces with a ball-end milling tool. Different CAM strategies create different toolpaths. This makes it possible to examine the effect of the machining direction on the surface roughness, the shape accuracy and the profile error. Changes in cutting parameters have an effect on these properties too, which have been investigated. During the production of the test pieces, the milling forces were measured, from which important conclusions can also be drawn.
\end{abstract}

Keywords: free-form milling; ball-end milling; geometric tolerance; surface roughness; cutting force; CAM strategies

\section{Introduction}

The free-form surface can be encountered in many places in machine and tool design. The forming of car body elements, or injection mould tools contain free form surfaces, where the machining is challenging thanks to the high accuracy and productivity demands.

Based on the work of other researchers, the studied circumstances can be classified into seven different groups in the case of free-form surface milling.

CAD: The first problem is, how to design and describe the free-form surfaces. The development of CAD systems solve this problem, but the different file formats use different standard and non-standard descriptions. Ma et al. [1] presents the problems of construction and reconstruction of free form surfaces. Investigate the difference between the points of the real and the theoretical surface, the geometric error. 


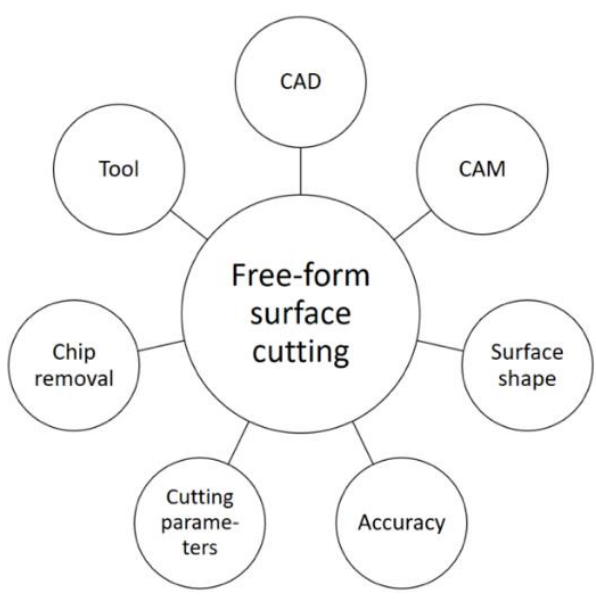

Figure 1

Investigation of milling of free-form surfaces

CAM: The free-form surfaces can be produced by using CAM systems. Different toolpaths can be created that affect the machining time and the quality of the machined surface. This aspect examines the possibilities offered by CAM systems. Different CAM strategies result different toolpaths, which defines productivity and the accuracy. Fountas and Vaxevanidis present the effect of different toolpaths on free-form surfaces [2]. Three different tool path strategies were compared, and the effect of the tool diameter and the stepover parameter were optimised considering the machining time and the surface deviation. Ižol et al. [3] compared different milling CAM strategies when milling free-form surfaces by examining the surface roughness and the machining time. Varga and Spisak study the effect of the different milling strategies to the form accuracy of a circular pocket in the case of aluminium alloy [4]. The value of the roundness deviation depends on the tool path strategy and the place (depth) of the measuring too. The different milling strategy has an effect not only on the cutting force and the surface roughness but on the tool wear also [5].

Surface shape: The geometry of the surface can be convex or concave which have influences on the machining process and the surface quality and accuracy. Huo et al. [6] determines the ideal toolpath based on the shape of the surface and its normal vector, for which it uses a fluid dynamics method. Käsemodel et al. [7] applies a CAD / CAM algorithm interface to study the shape of the free-form surface. This reduces cutting force, roughness and machining time.

Accuracy: The accuracy of the machined surface is examined from three aspects. The first is the dimensional accuracy: what is the size of the feature; the second is the geometric accuracy: how does the machined surface match the theoretical; and the third is the surface roughness. Fountas et al. studied shape accuracy while examining free-form surfaces [8]. There is a lot of research on mathematically 
predicting surface roughness. Seculic et al. [9] also investigated this using genetic and optimization algorithms.

Cutting parameters: The most frequently observed cutting parameters in the case of milling technology are the spindle speed $(n)$, the cutting speed $\left(v_{c}\right)$ the feed speed $\left(v_{f}\right)$ and the feed rate (f), the depth of cut $\left(a_{p}\right)$, and the width of cut $\left(a_{e}\right)$. Wojciechowski et al. [10] examines the effect of variable input parameters through cutting force measurement. Abainia and Bey [11] optimizes the feed rate based on the expected value of the cutting forces in order to obtain the best possible surface quality.

Chip removal: The examination of the cutting force, the chip shape, belongs to this aspect. It is important to examine the milling forces that arise during chip removal by having a detailed examination of the chip removal process. Mou et al. also examine force components arising during cutting, similar to this article [12]. During the test, the three components of the cutting forces were examined. The magnitude of the cutting force also provides important information about the machining of the free-form surface. Beňo et al. [13] the factors influencing the conditions of chip separation were investigated using the Khattree-Niak multivariate method.

Tool: The coating and the number of edges of the tools, the tool wear is also an important aspect. It can greatly affect surface roughness. Scandiffio et al. [14] investigated the working part of the tool during machining. The working section of the tool is constantly changing because of the changing surface inclination. This parameter significantly affects the surface quality.

Based on the classification, several factors affect the characteristics of free-form surfaces. During the design of the manufacturing process, the parameters of the cutting technology must be determined. In addition, the equipment's availability must be taken into account, both in terms of the production and the quality control. Some machine parts are made of difficult-to-machine materials and have complex geometries, which complicate their manufacturing $[15,16]$. The characteristics of each type of material have a large effect on the choice of machining methods, conditions, equipment, and the tools.

Geometric tolerances have an increasingly important role in the industry, defined and marked according to standards [17]. Such a standard (ISO 4287, ISO4288) also fixes the surface roughness, which is the micro-scale deviation of the surfaces. It defines a number of specifications and measurement details [18]. It may also be necessary to estimate the expected surface roughness when designing the machining process.

The accuracy of the free form surface has different aspects and several parameters have effect on it. In the current research the geometric, the dimensional accuracy, and the surface roughness are investigated in the case of ball-end milling of free form surfaces. We focus on the process planning and the application of CAM 
systems. In this paper, the effect of the different milling strategies on the surface roughness and the accuracy of the form surface is presented. Our aim is to support the work of CAM programmers in the selection of the most appropriate milling strategy.

\section{Materials and Methods}

The size of the test part was $80 \times 80 \times 30 \mathrm{~mm}$, and the main feature is a cylindrical surface with a $45 \mathrm{~mm}$ radius, which is connected to a horizontal plane with a 10 $\mathrm{mm}$ radius (Figure 2$)$. A concave $(\mathrm{CV})$ and a convex $(\mathrm{CX})$ part were created, in order to compare the effect of the nature of the surfaces. The height and the depth of the profile were $9.2 \mathrm{~mm}$.

The material of the test parts was $42 \mathrm{CrMo} 4(1.7225 ; \mathrm{Rm}=1000 \mathrm{MPa})$ low alloy steel (Table 1), which is one of the chromium, molybdenum, manganese low alloy steel material with high fatigue strength and good low-temperature impact toughness. $42 \mathrm{CrMo} 4$ alloy steel is widely used for engineering steel purposes.

The machining was performed by a Mazak 410 A-II CNC machining centre. The tools were always fixed in an EMUGE-FRANKEN SK40 cold shrink clamp (powRgrip). Flooded cooling-rinsing lubrication (Aquamet 40, 6-8\% emulsion, yield about $30 \mathrm{l} / \mathrm{min}$ ) was used for the measurements. The CNC programs were generated by CATIA v5 CAD/CAM system. During the finishing the applied cutting tool was a Fraisa X7450.450 ball-end milling cutter with $10 \mathrm{~mm}$ diameter $\left(D_{c}=10 \mathrm{~mm}\right)$ and the number of teeth was $4(\mathrm{z}=4)$.
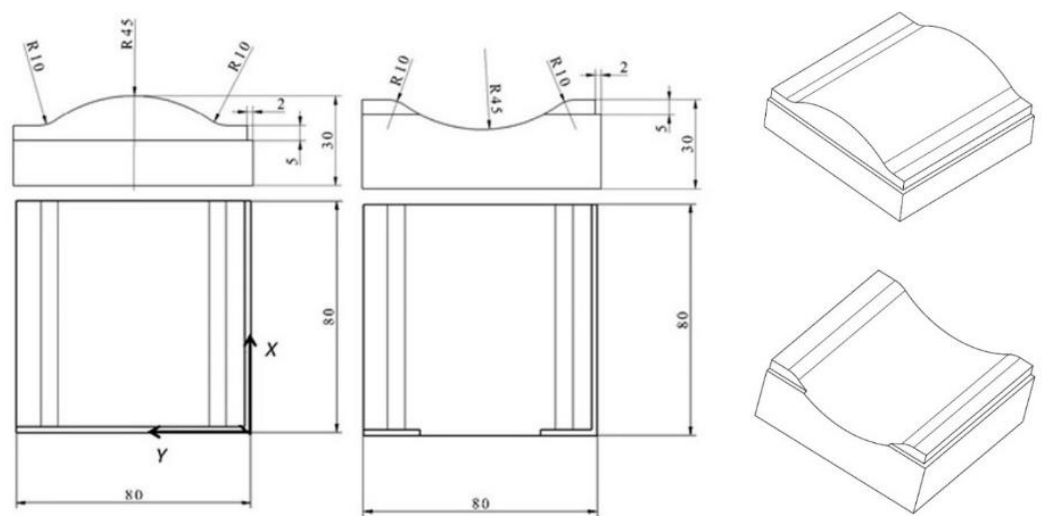

Figure 2

Convex $(\mathrm{CX})$ and concave $(\mathrm{CV})$ test part

The surface roughness was measured by Mahr Perten GD120 test instrument, which works with the contact method. 
The $\mathrm{Ra}$ and $\mathrm{Rz}$ parameters were measured during the test. For a better comparison of the surface roughnesses, the measuring was performed only in $\mathrm{x}$-direction in 7 different positions. Table 1 shows the angles of the surface normal vector.
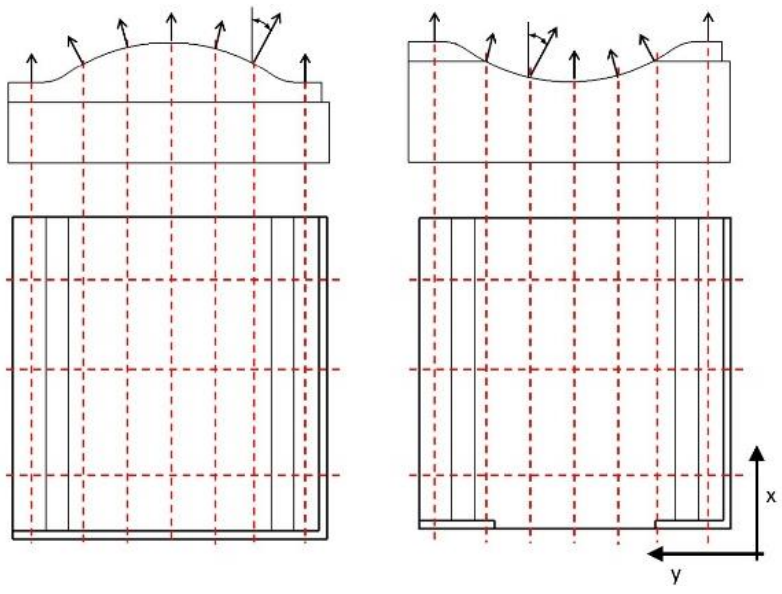

Figure 3

Measuring positions and normal vectors $\left({ }^{\circ} / 32.2^{\circ} / 15.5^{\circ} / 0^{\circ} /-15.5^{\circ} /-32.2^{\circ} / 0^{\circ}\right)$

Table 1

Angles of the surface normal vector

\begin{tabular}{|l|c|c|c|c|c|c|c|}
\hline Measuring points (y) & 2 & 14 & 26 & 38 & 50 & 62 & 74 \\
\hline $\mathrm{CX}$ angles & $0^{\circ}$ & $32.2^{\circ}$ & $15.5^{\circ}$ & $0^{\circ}$ & $-15.5^{\circ}$ & $-32.2^{\circ}$ & $0^{\circ}$ \\
\hline $\mathrm{CV}$ angles & $0^{\circ}$ & $-32.2^{\circ}$ & $-15.5^{\circ}$ & $0^{\circ}$ & $15.5^{\circ}$ & $32.2^{\circ}$ & $0^{\circ}$ \\
\hline Absolute value of angles & $0^{\circ}$ & $32.2^{\circ}$ & $15.5^{\circ}$ & $0^{\circ}$ & $15.5^{\circ}$ & $32.2^{\circ}$ & $0^{\circ}$ \\
\hline
\end{tabular}

The current research focuses on the investigation of geometric tolerances of freeform surfaces created with a ball-end milling. Two types of geometric tolerances were studied, cylindricity (Cyl) and surface profile (SPE) tolerance. Based on the ISO 1101 standard the cylindricity error is the radial distance of the two cylinders (Figure 4), which have the same axis and covers the investigated surface. So the cylindricity describes the accuracy of the geometric shape, ignoring its position. The cylindricity tolerance can be applied only in the case of cylindrical surfaces. The surface profile error can also be applied to non-cylindrical surfaces. The surface profile tolerance zone is limited by two parallel envelope surfaces, which are parallel with the theoretical surface too. 

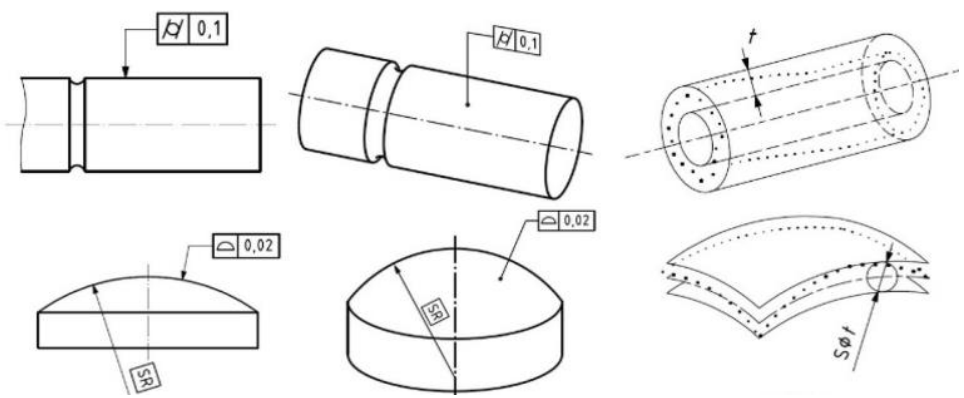

Figure 4

The definition of cylindricity and surface profile error based on ISO 1101

Surface points were measured by a Mitutoyo Crysta-Plus 544 coordinate measuring machine. 49 points were measured on the surface along a $7 \times 7$ grid. The evaluation of the geometric error was determined based on measured points by Evolve Smart Profile v6 software (Figure 5), which can compare the measured point to the theoretical CAD model of the test part. The nominal radius of the cylindrical surface was also measured during the test by the Evolve Smart Profile v6 software.

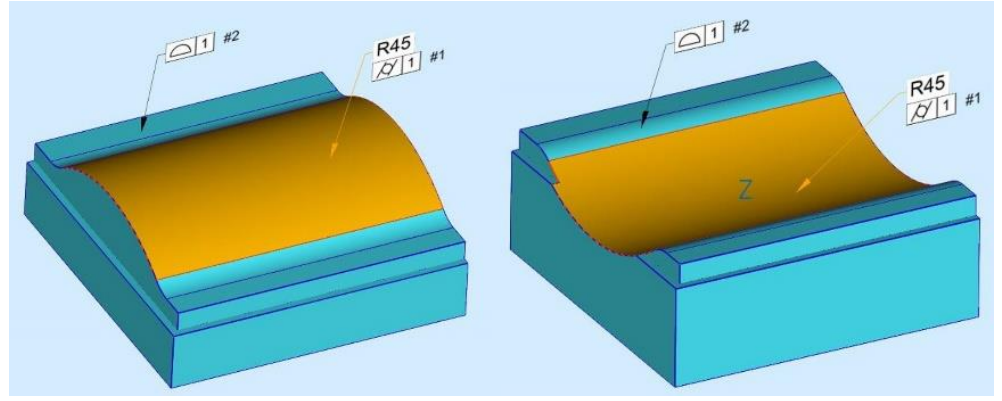

Figure 5

Definitions of geometric tolerances in Smart Profile and test parts

Cutting force measurement was performed during the cutting process of the second stage. KISTLER 5019 type, 3 component force measuring device was used. The data were evaluated by DynoWare software. The force measure was performed by $500 \mathrm{~Hz}$ frequency, so data was recorded in every 0.002 seconds. Considering the spindle speed, 0.002 seconds means $61.2^{\circ}$ revolution of the tool.

\subsection{Investigation of Various Tool Path Strategies}

Two different test series were performed. In the first phase, the effect of the tool path strategies was investigated, and the surface roughness and the geometrical errors were compared. In the second phase, the effect of the cutting parameters was studied in the case of the selected toolpath strategy. 
CX-1; CV-1

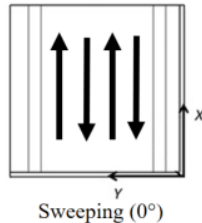

CX-6; CV-6

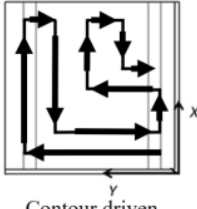

Contour driven

with paralel contour
$\mathrm{CX}-2 ; \mathrm{CV}-2$

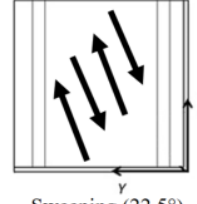

CX-7; CV-7

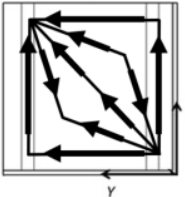

Contour driven

with two guide
CX-3; CV-3
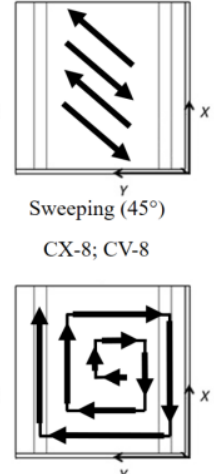

Spiral milling

From inside to

outside
CX-4; CV-4

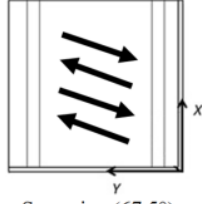

Sweeping $\left(67.5^{\circ}\right)$

CX-9; CV-9

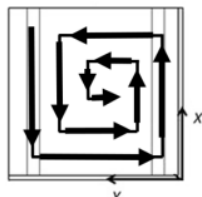

Spiral milling

From outside

to inside
CX-5; CV-5

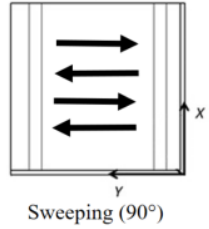

CX-10; CV-10

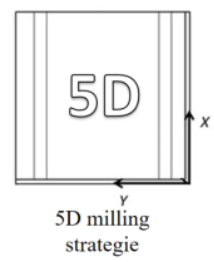

Figure 6

CAM strategies

During the first test series the cutting parameters were the same: cutting speed $\mathrm{v}_{\mathrm{c}}=$ $160 \mathrm{~m} / \mathrm{min}$; spindle speed $\mathrm{n}=5100 \mathrm{rpm}$; feed per tooth $\mathrm{f}_{\mathrm{z}}=0.08 \mathrm{~mm}$; feed speed $\mathrm{v}_{\mathrm{f}}=1650 \mathrm{~mm} / \mathrm{min}$; the depth of cut $\mathrm{a}_{\mathrm{p}}=0.3 \mathrm{~mm}$; the width of the cut $\mathrm{a}_{\mathrm{e}}=0.15$ $\mathrm{mm}$. The width of cut means the distance between the tool paths, and it has a critical effect on the surface quality.

The milling of the test surfaces was performed by different strategies, as sweeping (with variable sweeping direction), spiral milling (from inside to outside), spiral milling (from outside to inside), contour driven (with two guides), contour driven (with parallel contour) and one 5D milling strategy (Figure 6).

\subsection{Investigation of Various Cutting Parameters}

In the second phase, the effect of the cutting parameters was investigated. 8 more test pieces were produced, four convex (CX) and four concaves (CV). During the manufacture of the test pieces, the roughing and pre-finishing parameters were same. Table 2 shows the cutting parameters of the test. The feed per tooth and the width of cut were varied. Test parts No4 were add to the comparison. During the production of each new test piece, only one parameter changed, the other manufacturing parameters were the same. 
Table 2

Cutting parameters used in the test

\begin{tabular}{|l|c|c|c|c|c|}
\hline Test part id. & $\begin{array}{c}\text { CX-15; } \\
\text { CV-15 }\end{array}$ & $\begin{array}{c}\text { CX-16; } \\
\text { CV-16 }\end{array}$ & $\begin{array}{c}\text { CX-04; } \\
\text { CV-04 }\end{array}$ & $\begin{array}{c}\text { CX-17; } \\
\text { CV-17 }\end{array}$ & $\begin{array}{c}\text { CX-18; } \\
\text { CV-18 }\end{array}$ \\
\hline Cutting speed $\mathrm{v}_{\mathrm{c}}[\mathrm{m} / \mathrm{min}]$ & \multicolumn{5}{|c|}{160} \\
\hline Spindle speed $\mathrm{n}[\mathrm{rpm}]$ & \multicolumn{5}{|c|}{5100} \\
\hline Feed per tooth $\mathrm{f}_{\mathrm{z}}[\mathrm{mm}]$ & 0.08 & 0.08 & 0.08 & 0.12 & 0.16 \\
\hline Feed speed $\mathrm{v}_{\mathrm{f}}[\mathrm{mm} / \mathrm{min}]$ & 1630 & 1630 & 1630 & 2450 & 3260 \\
\hline Depth of cut $\mathrm{a}_{\mathrm{p}}[\mathrm{mm}]$ & \multicolumn{5}{|l}{0.3} \\
\hline Width of cut $\mathrm{a}_{\mathrm{e}}[\mathrm{mm}]$ & 0.35 & 0.25 & 0.15 & 0.15 & 0.15 \\
\hline
\end{tabular}

\section{Result and Discussion - Investigation of Various CAM Strategies}

Based on the results of the presented milling tests, it can be stated that the surface normal vector (inclination of the surface) has an effect on the surface roughness. Surface roughness is worse on horizontal or near-horizontal surfaces. These surfaces are located at both ends and in the middle of the test pieces as the diagrams show (Figure 7). At these places, the value of the normal vector is $0^{\circ}$. A "W" shape is drawn for each diagram. In some cases, the differences are smaller, but the character can be recognized. The measuring direction modifies the values because of the nature of the contact measuring method. The highest values are located where the milling direction is perpendicular to the measurement direction.

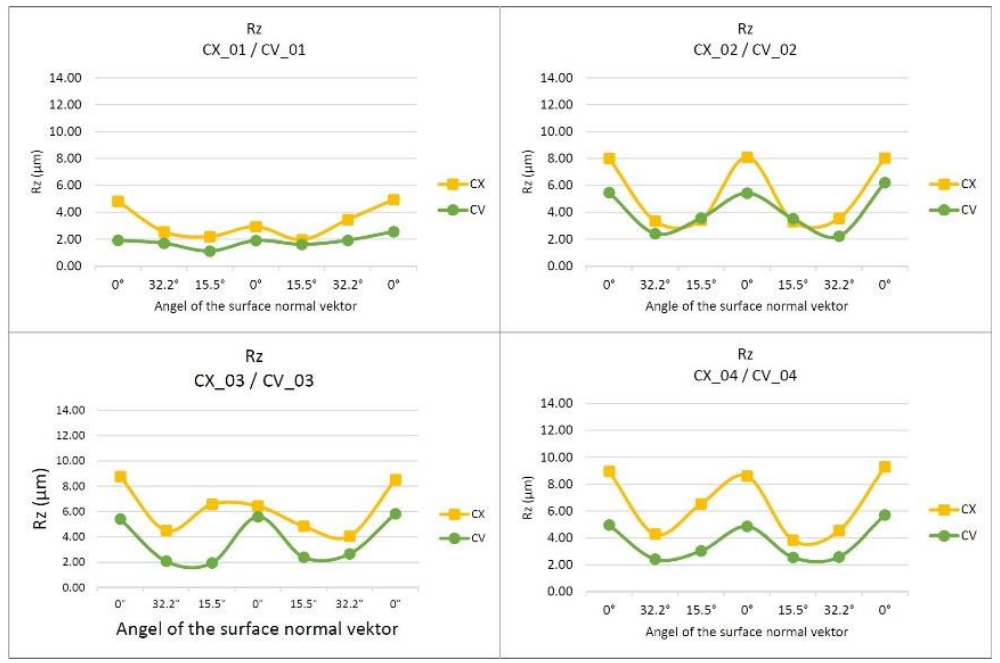



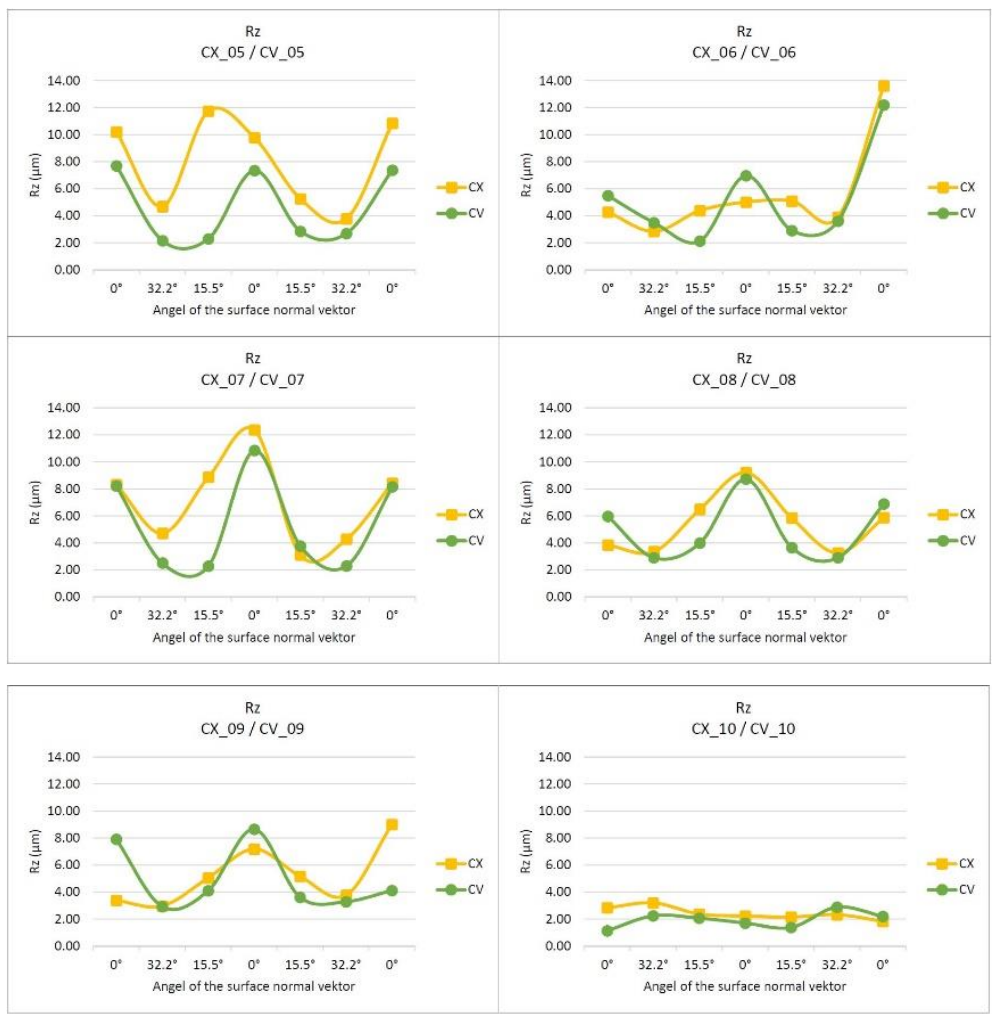

Figure 7

$\mathrm{Rz}$ surface roughness in different normal vectors (CV-CX 1-10)

The average surface roughness was calculated from all measured values. Figure 8a shows the average surface roughness of the test pieces. The diagram shows that for the first five test pieces that the change in sweeping direction affects the magnitude of roughness. Based on this, it can be stated that the direction of a sweeping strategy influences the surface roughness. From x-milling direction $\left(0^{\circ}\right)$ to y-direction $\left(90^{\circ}\right)$ the surface roughness increases in the case of concave test pieces. This observation wasn't made for the concave pieces. It can also be seen that better roughness values are obtained for test piece No10. In this test piece, the concave and convex roughness values almost coincide.

The measured roughness value is influenced by a number of factors, such as the test piece geometry, the tool, the cutting parameters, the nature of the toolpath, the properties of the manufacturing machine, and the method of measuring the roughness.

The milling strategies have an effect on dimensional accuracy also. The dimensional accuracy is the part of macro-scale errors and means the error of size. Figure $8 \mathrm{~b}$ shows the deviations of the machined surface from the nominal 
radius value $(45 \mathrm{~mm})$. Based on the obtained results, it can be said that the convex test pieces are below the nominal radius value, while the concave test pieces are above it. The five-axis machining does not fit in line in this case either (CV-10; $\mathrm{CX}-10)$. The reason for this is the constant position of the tool relative to the surface.

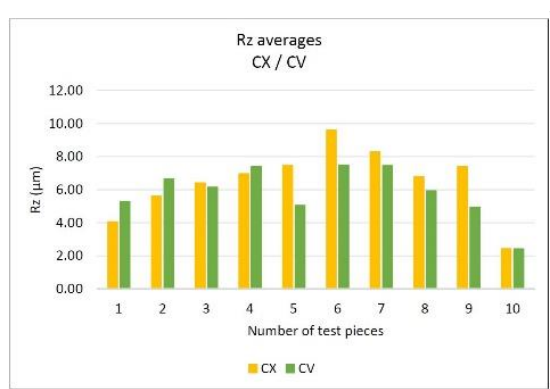

a)

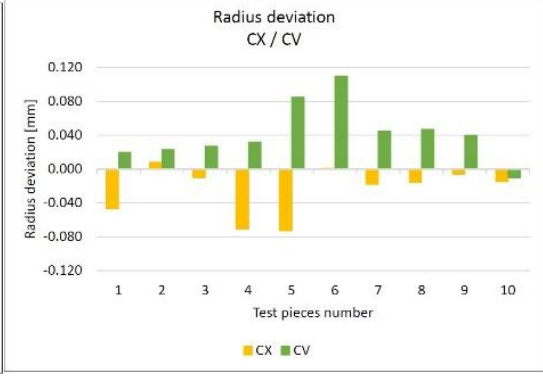

b)

Figure 8

$\mathrm{Rz}$ averages and radius for all data (CV1-10 - CX1-10)

The second type of macro scale error is the group of geometric errors. The values of the different geometric errors can be seen in Figure 9. The values of the cylindricity and surface profile error are very similar because of the similarity of the definitions. The first 5 test parts (CX1-5; CV1-5) show the effect of the feed direction. The investigated geometric errors are smaller when the milling is performed in x-direction (1), where the z-coordinate of the surface is the same. In the y-direction (5) the z-level of the tool path changes, other section of the tool is worked and it results in a larger error. The other milling strategies (6-10) result in smaller geometric errors. In all cases, the convex surfaces have better accuracy than the convex. The values of the cylindricity error are smaller because of the less number of freedom of the tolerance zone. The difference of the geometric error between the convex and concave parts is larger in the case of sweeping strategies (1-5). When combined strategies are used (6-9) the differences are smaller, but the 5D milling (10) ensures the smallest difference.

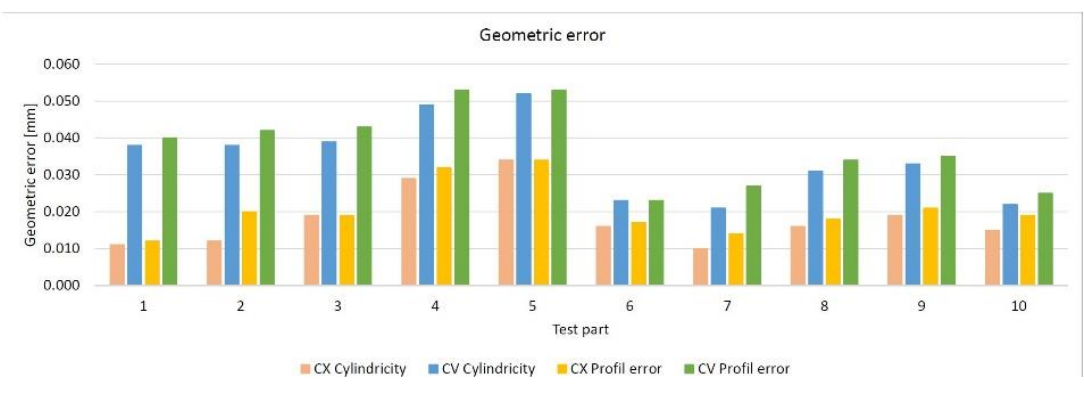

Figure 9

Values of geometric error (CV1-10-CX1-10) 


\section{Result and Discussion - Investigation of Various Cutting Parameters}

During the second phase, the effect of the cutting parameters were investigated. The CV-4 and CX-4 were the basis of the comparison. In the case of test pieces CV-15, CX15, CV16, CX16, the width of cut was changed (Table 2), and at two test pieces, the feed per tooth was changed (CV17, CX17, and CV18, CX18).

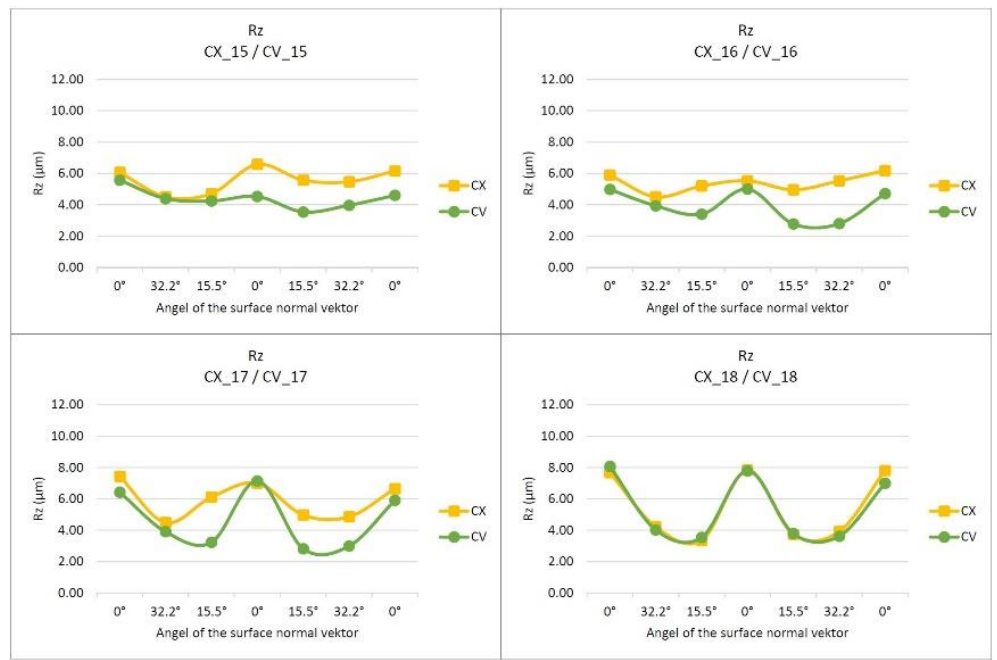

Figure 10

$\mathrm{Rz}$ surface roughness in different normal vectors (CV-CX 15; 16;17;18)

The "W" character of the diagrams of surface roughness can be recognised (Figure 10). Generally, the concave surfaces have smaller surface roughness because of the better insertion of the ball-end tool and surface radius.

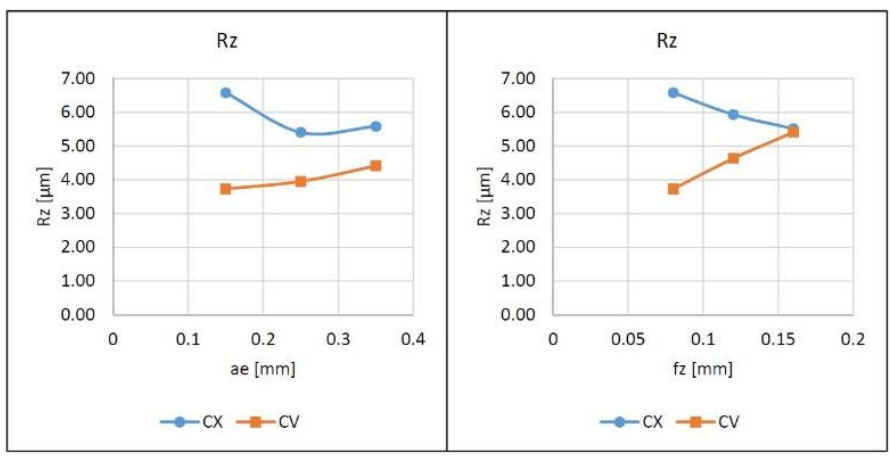

Figure 11

The effect of width of cut and feed per tooth on the surface roughness 
The effect of the investigated cutting parameters on the micro and macro accuracy can be seen on the next figures. In the case of surface roughness (the Rz parameter is presented only) the parameters have an inverse effect in the case of convex and concave test surfaces (Figure 11). The surface roughness is increasing in the case of a concave surface parallel with the width of cut and feed per tooth. However, the $\mathrm{Rz}$ value of the convex surface decreases. This observation is remarkable. The concave surfaces have better roughness.

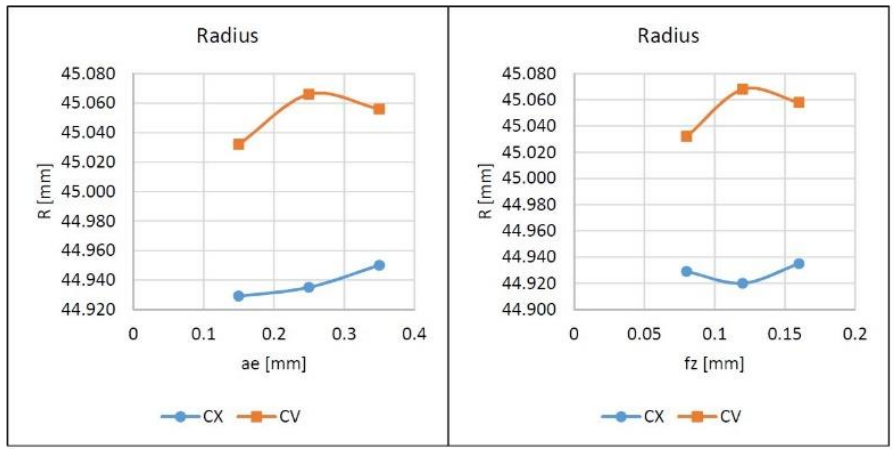

Figure 12

The effect of width of cut and feed per tooth on the radius

This inverse effect can be observed in the case of the value of the radius (Figure 12). The convex surfaces have a smaller radius and the width of cut increases. In the case of a concave surface, the largest $a_{e}$ decreases the value. The feed per tooth initially decreases, later increases the radius of the convex surface. In the case of a concave surface, the value of the radius is larger, and it shows the inverse change. The changing of the radius due to the parameters is very small (0.02-0.03 mm).

The geometric errors show a very similar look. As Figure 13 shows, the cylindricity error is smaller in the case of a convex surface, but the difference decreases when the width of cut and the feed is larger. The cylindricality shows that concave test pieces are more inaccurate than convex ones especially in the case of test part No4 ( $\mathrm{ae}=0.15 \mathrm{~mm} ; \mathrm{fz}=0.075 \mathrm{~mm})$. However, there is no significant difference between the other parts.

At the profile error (Figure 14) the parameters show similar tendencies, but changing of the error is smaller in the case of convex surfaces. The profile error values show that the error also decreases when the feed rate increases. However, the width of the cut does not significantly affect it. The value of the change is 0.01 $\mathrm{mm}$ in case of the convex parts and $0.03 \mathrm{~mm}$ in case of concave surfaces. 


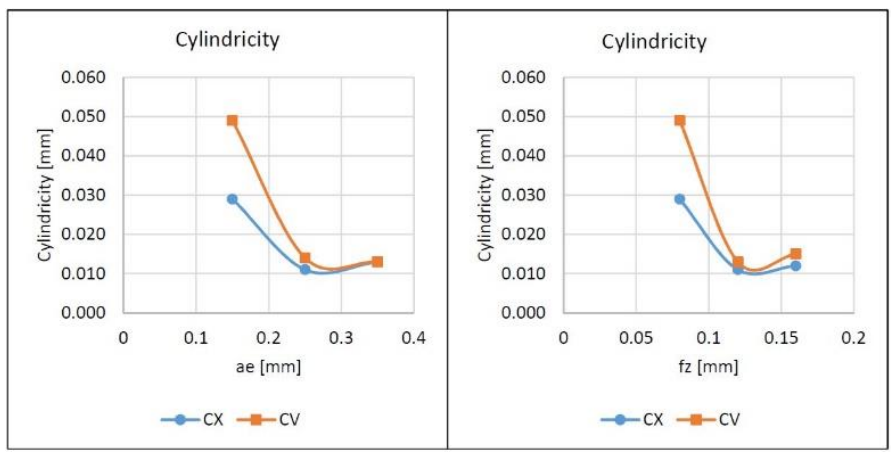

Figure 13

The effect of width of cut and feed per tooth on the cylindricity

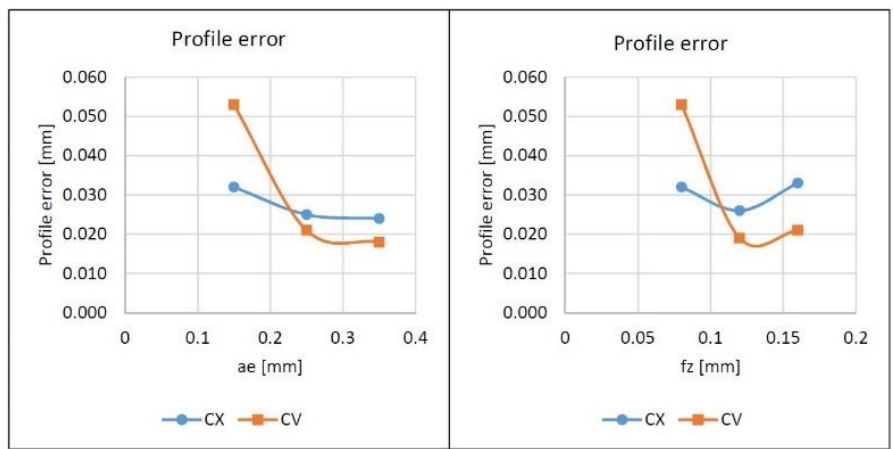

Figure 14

The effect of width of cut and feed per tooth on the profile error

The source of the geometric error is the load of the cutting tool and the deformation of the system. Three force components were measured based on the direction of the coordinate system, and the resultant cutting force was calculated (Figure 15).
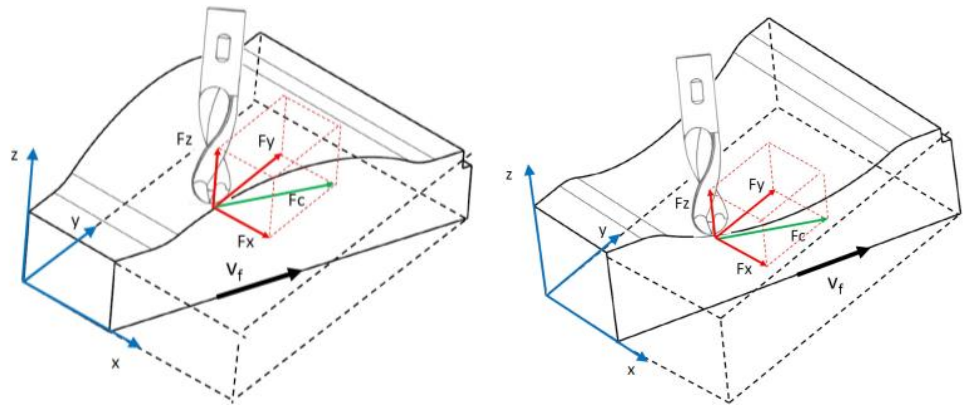

Figure 15

The cutting force and the force components in case of the convex and the concave parts 
The measuring frequency was $500 \mathrm{~Hz}$, which means 0.002 time resolution, but it means $61.2^{\circ}$ revolution of the tool. Therefore, the changing of the values and the range of the force components are very large and fuzzy (Figure 16a). The 61.2 resolution means that in some cases there are no connection between the tool and the workpiece. In order to have better data processing a filtering function was used: the average values of 25 measured data were calculated and marked by the index ' 25 '. The 25 data cover 0.05 seconds. Figure $16 \mathrm{~b}$ shows the filtered data of CX-15 part.

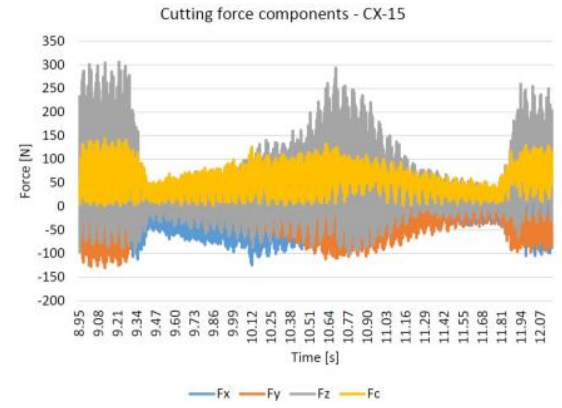

a)

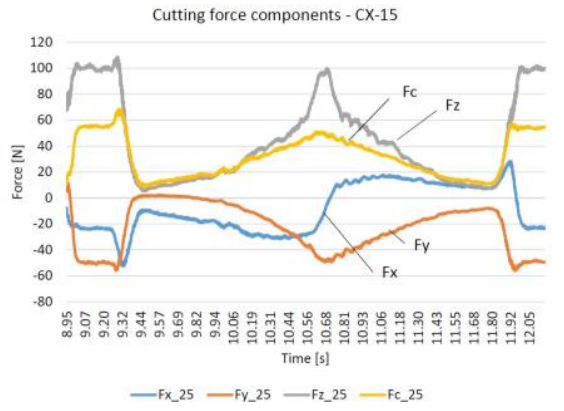

b)

Figure 16

The measured and filtered force values in case of CX-15

On Figure 17 the relationship between the force components and the character of the surface can be observed. The milling was performed left to right.

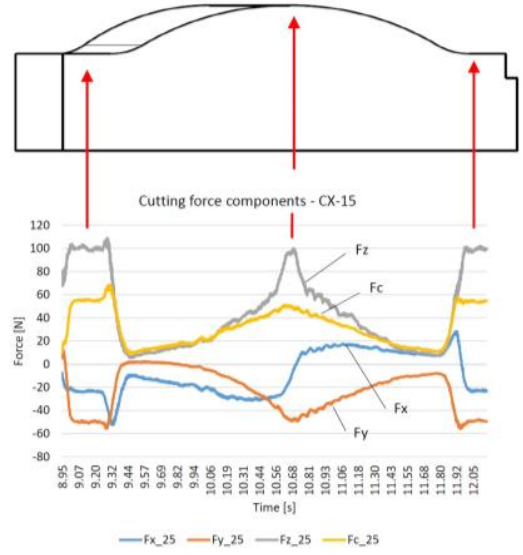

a)

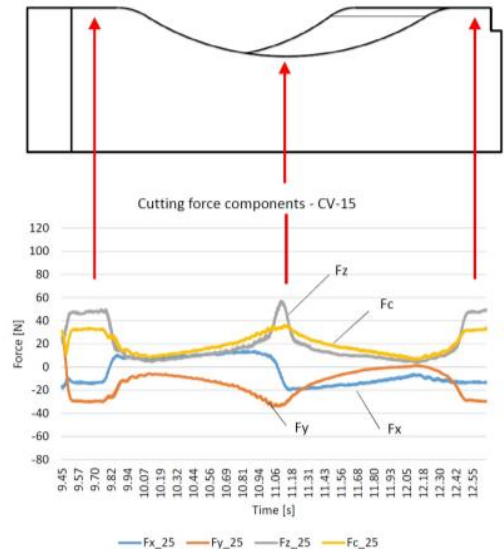

b)

Figure 17

The average value of the force components along the surface

The Fz component (axial direction of the tool) has maximum value at the horizontal sections. The decreasing of the Fz is very fast after the initial plate, and then a slow increase can be seen. The Fx component has a negative value at the 
beginning, and it changes to a positive at the top point in the case of a convex part. In the case of a concave part, the tendency is reversed. The Fy component there is in the negative region, it has a maximum value at the horizontal sections, but the dynamic of the changes is different at the two sides. Hereinafter only the resultant forces $(\mathrm{Fc})$ will be compared, which is the vectorial sum of $\mathrm{Fx}$ and Fy components.
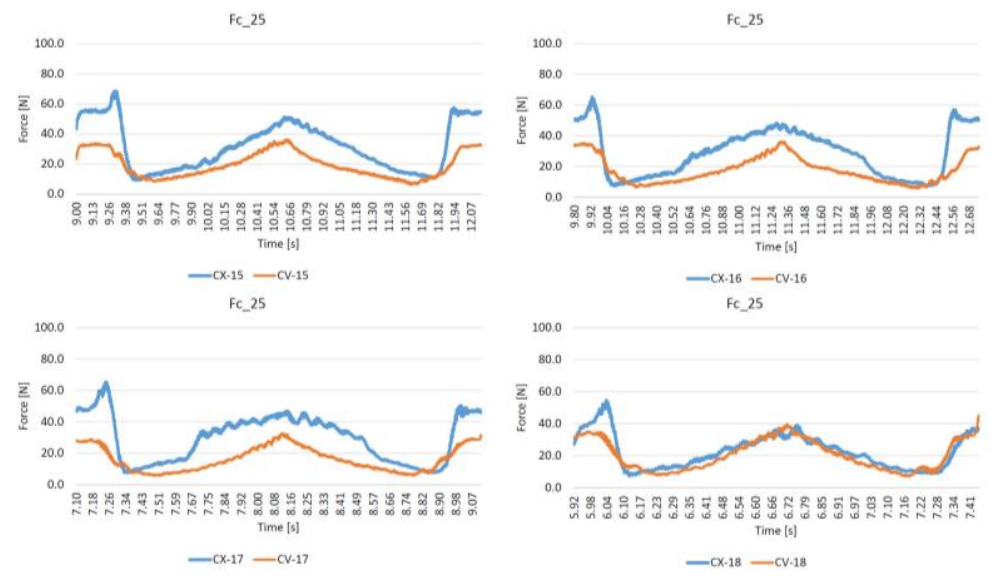

Figure 18

The resultant forces $(\mathrm{Fc})$

Figure 18 shows the Fc forces based on the average of 25 data in the case of the 8 specimens. The convex parts have a larger force, but the character of the curves is very similar. The average values were calculated of the Fc_25 resultant forces. In the case of concave parts $(\mathrm{CV})$ the effect of the $\mathrm{fz}$ and ae is well recognised, the decreasing width of cut $\left(a_{e}\right)$ decreases the $F c$ a little, but the increasing feed $\left(f_{z}\right)$ increases the force on a larger scale. This tendency is similar to the effect of cutting parameters on the surface roughness. In the case of the CX-17, the average value of the cutting force is larger than expected because of the early force increase in the first section.

The changing resultant cutting force has an effect on the geometric error of the surface, as Figure 19 shows. In the case of a convex part the higher force causes a higher profile error. But the error map shows, that at the sides and in the middle region, where the cutting force has a maximum value, the error is positive, the measured surface there is above the theoretical surface. On the other hand, if the force is smaller, the profile error becomes negative, and the machined surface will be under-milled.

The effect of the sudden decreasing of the resultant force after the initial horizontal section can be seen on the error map too. The dark blue regions indicate large negative errors. 


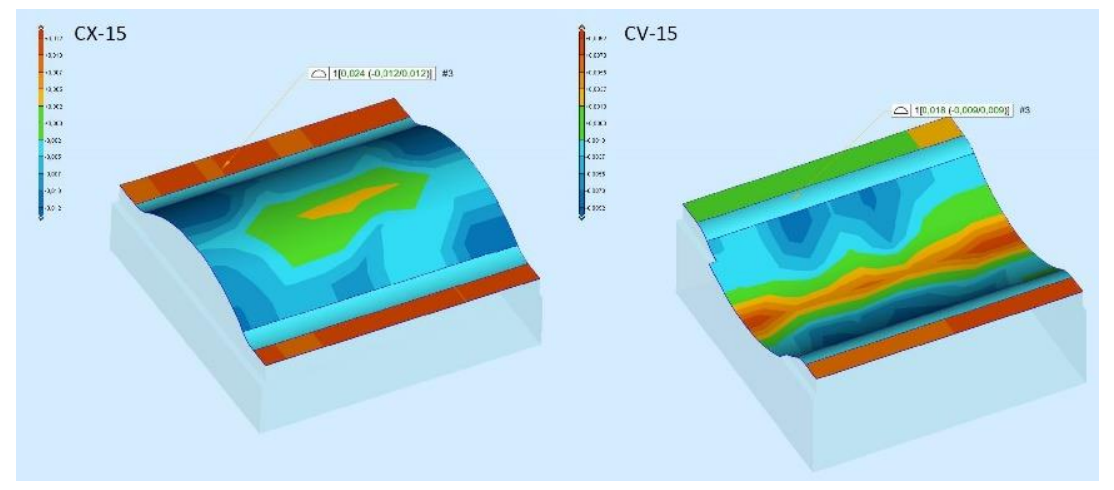

Figure 19

Profile error maps of CX-15 and CV-15

\section{Conclusion}

There are several ways to qualify manufactured parts. It can be classified on the basis of surface roughness, shape accuracy, and dimensional accuracy. From an industrial point of view, accuracy requirements are becoming increasingly important. The current research focuses on the examination of the CAM systemgenerated toolpaths and cutting parameters. The free-form test parts were machined by a ball-end milling tool. In the current paper, we examined the dimensional accuracy, the surface roughness, the geometric error, and the milling force. In the first half of the experiment, convex and concave test parts were machined using different toolpath strategies. In the second half of the experiment, the effect of the width of the cut (distance between the tool paths) and the feed were investigated.

Based on the results, it was found that the surface roughness, the dimensional error, and the geometric error represent different aspects of accuracy, but are not independent of each other.

In case of the test parts No1-5, the direction of the tool path between the $\mathrm{x}$ and $\mathrm{y}$ axes increased the surface roughness, but it is not affected by the nature of the surfaces (convex or concave). The surface roughness of the test parts No6-9 is similar to the previous five. Test part No10 hangs out of line, but that was to be expected, thanks to the 5-axis machining, when the cutting tool can be tilted during machining, and thus better cutting circumstances can be achieved.

Based on the obtained data, it can be seen that the surface roughness of the concave test parts is better than that of the convex pieces. This tendency was not affected by feed rate or cutting width. The surface roughness value is greatly influenced by the surface normal vector. Where the vector is parallel with the tool axis, there are the worst roughness values because of the ball-end mill and the test piece contact on the smallest surface and working diameter. 
The investigation of the feed rate confirmed that the surface roughness deteriorates with increasing feed rate and the change in cutting width has a smaller effect.

The dimensional accuracy was tested by examining the radius of the cylindrical surface. The nominal value was $45 \mathrm{~mm}$. The results showed that the radius of the concave test pieces is larger than the nominal value and in the case of convex test pieces, it was smaller. This is not observed in case of five-axis machining, where both test parts had smaller radius. This is due to the homogeneity of the machining.

The investigation of the cylindricity error suggests that concave pieces are more inaccurate in all cases than convex pieces. This suggests that the nature of the geometry greatly affects cylindricity error. The dimensional accuracy is more affected by milling direction than cutting parameters. The cutting width and the feed rate have no significant effect on the cylindricity.

The profile error was also larger for concave test parts, so the nature of the geometry has a large effect on this type of error. The direction of machining also greatly influences their value. For the convex and the concave test pieces, the deviation can be up to twice. However, it is not particularly affected by the feed rate and the cutting width. Overall, the milling direction has a greater effect on shape tolerance than the cutting parameters.

In the case of convex parts, the cutting force is higher, and at the horizontal surface sections, the force has maximum value. The size of the cutting width has little effect on the force. The change in feed rate requires further research. Examination of the y-direction forces shows that the tool requires a force in the opposite direction when traveling on an uphill or downhill path. The inflection point of the diagrams indicates this. In further research the deeper analyses of the cutting force and the force components is necessary. The effect of tool deformation on shape accuracy also requires further investigation.

The results are summarised as follows:

From the surface roughness point of view, the direction of the surface normal vector is the most influential factor. Five-axis machining is not better than threeaxis machining in terms of surface roughness, the average value is higher, but the constant along the surface. It is also found that the surface roughness deteriorates with increasing feed rate.

In terms of shape accuracy, the milling direction has a greater effect on shape accuracy than the cutting parameters. And the convexity of the workpiece has a strong influence on the rollability.

In terms of machining force, it can be stated that higher cutting forces are required to machine convex parts. 


\section{References}

[1] Ma W., He G., Han J., Xie Q.: Error compensation for machining of sculptured surface based on on-machine measurement and model reconstruction. The International Journal of Advanced Manufacturing Technology 106:3177-3187(2020) doi: 10.1007/s00170-019-04862-0

[2] Fountas N. A., Vaxevanidis N. M.: Intelligent 3D tool path planning for optimized 3-axis sculptured surface $\mathrm{CNC}$ machining through digitized data evaluation and swarm-based evolutionary algorithms. Measurement 158(2020) doi:10.1016/j.measurement.2020.107678

[3] Ižol P., Vrabel' M., Maňková I.: Comparison of Milling Strategies when Machining Freeform Surfaces. Material Sience Forum 862:18-25(2016) doi: 10.4028/www.scientific.net/MSF.862.18

[4] Varga J., Spišák E.: Influence of the milling strategies on roundness of machined surface. Acta Mechanica Slovaca 24(3):20-27(2020) doi: 10.21496/ams.2020.001

[5] Mali R. A., Aiswaresh R., Gupta T. V. K.: The influence of tool-path strategies and cutting parameters on cutting forces, tool wear and surface quality in finish milling of Aluminium 7075 curved surface. The International Journal of Advanced Manufacturing Technology 108(5):589601(2020) doi: 10.1007/s00170-020-05415-7

[6] Huo G., Jiang X., Su C., Lu Z., Sun Y., Zheng Z., Xue D.: CNC tool path generation for freeform surface machining based on preferred feed direction field; International Journal of Precision Engineering and Manufacturing 20:777-790(2019) doi: 10.1007/s12541-019-00084-2

[7] Käsemodel R. B., de Souza A. F., Voigt R., Basso I., Rodrigues A. R.: CAD/CAM interfaced algorithm reduces cutting force, roughness, and machining time in free-form milling. The International Journal of Advanced Manufacturing Technology 107:1883-1900(2020) doi: 10.1007/s00170-020-05143-x

[8] Fountas N. A., Benhadj-Djilali R., Stergiou C. I., Vaxevanidis N. M.: An integrated framework for optimizing sculptured surface $\mathrm{CNC}$ tool paths based on direct software object evaluation and viral intelligence; Journal of Intelligent Manufacturing 30:1581-1599(2019) doi: 10.1007/s10845-017$1338-y$

[9] Sekulic M., Pejic V., Brezocnik M., Gostimirović M. Hadzistevic M.: Prediction of surface roughness in the ball- end milling process using response surface methodology, genetic algorithms, and grey wolf optimizer algorithm. Advances in Production Engineering \& Management; 13(1):1830(2018) doi: 10.14743/apem2018.1.270

[10] Wojciechowski S., Maruda R. W., Barrans S., Nieslony P., Krolczyk G. M.: Optimisation of machining parameters during ball end milling of hardened 
steel with various surface inclinations. Measurement 111:18-28(2017) doi:10.1016/j.measurement.2017.07.020

[11] Abainia S., Bey M.: Feedrate optimization for 3-axis sculptured surfaces finishing using flat-end tool. Journées de Mécanique de l'EMP (JM'11EMP) (2018)

[12] Mou W., Zhu S., Zhu M., Han L., Jiang L.: A Prediction Model of Cutting Force about Ball End Milling for Sculptured Surface. Mathematical Problems in Engineering 1389718(2020) doi: 10.1155/2020/1389718

[13] Beňo J, Maňková I, Ižol P, Vrabel' M.: An approach to the evaluation of multivariate data during ball end milling free-form surface fragments. Measurement 84:7-20(2016) doi: 10. 1016/j.measurement.2016.01.043

[14] Scandiffio I., Diniz A. E., de Souza A. F.: Evaluating surface roughness, tool life, and machining force when milling free-form shapes on hardened AISI D6 steel. The International Journal of Advanced Manufacturing Technology 82(9):2075-2086(2016) doi: 10.1007/s00170-015-7525-0

[15] Kaya E., Akyuz B.: Effects of cutting parameters on machinability characteristics of Ni-based superalloys: A review. Open Engineering 7(1):330-342(2017) doi: 10.1515/eng-2017-0037

[16] Olufayo O. A., Che H., Songmene V., Katsari C., Yue S.: Machinability of Rene 65 superalloy. Materials 12(12):2034(2019) doi: $10.3390 / \mathrm{ma} 12122034$

[17] ISO 1101-2017 Geometrical product specifications (GPS) - Geometrical tolerancing - Tolerances of form, orientation, location and run-out

[18] Farkas G.; Drégelyi-Kiss Á.: Measurement uncertainty of surface roughness measurement. IOP Conference Series: Materials Science and Engineering 448(1):012020(2018) doi:10.1088/1757-899x/448/1/012020 